\title{
Regression of Kaposi's Sarcoma in a Sudanese kidney Transplant Recipient after Conversion to Sirolimus: a Focus on a Common Clinical Problem
}

\author{
Mohamed E A Yousif ${ }^{* 1}$ and A M EL Hassan ${ }^{2}$ \\ 1. Consultant Nephrologist, Nephrology Unit, Ibn Sina Hospital, Khartoum, Sudan \\ 2. Emeritus Professor, Institute of Endemic Diseases, University of Khartoum
}

\section{Editor's note:}

The case presented here describes a problem which is not well appreciated by most physicians working with renal patients. Kaposi sarcoma is relatively common among Sudanese kidney-transplanted patients, with a prevalence of approximately 1.5\% (unpublished data). The following case demonstrates the typical presentation and management.

\section{Introduction}

A markedly increased incidence of malignancy in transplant recipients is well recognized. The rates for most malignancies are higher after kidney transplantation compared with the general population. The largest experience on the relative incidence and types of malignancy comes from an analysis of over 35,000 first time renal transplant recipients. Compared with the general population, there is a twenty-fold increase in non-melanoma skin cancers, Kaposi's sarcoma, and nonHodgkin's lymphomas [1]. When all malignancies are considered together, the average age at presentation is 40 years and the average time latency after transplantation is 3-5 years. A shorter time latency of 13-21 months has been observed for Kaposi Sarcoma [2].

Kaposi's sarcoma was first described by Moritz Kaposi in 1872 as a disease in elderly men of Mediterranean or Jewish descent. It is a well-recognized post-transplant malignancy in individuals of Mediterranean, Jewish, Arabic, Caribbean, or African descent due to the geographical distribution of human herpes virus 8 (HHV8). In this study we describe a kidney transplant recipient of Arabic/African descent who developed Kaposi's sarcoma shortly after transplantation.

* Corresponding author; Nephrology Unit, Ibn Sina Hospital, Khartoum, Sudan; Secretory general of the Sudanese Nephrology Society.

Email: aminawd@ hotmail.com

\section{Case presentation}

The patient is a 56-year-old male who was diagnosed to have chronic kidney disease (CKD) in 2008. He underwent pre-emptive kidney transplantation in July 2010 from live-related donor, his son, with three mismatches in Saudi Arabia. He was neither hypertensive nor diabetic before transplantation. He used to be a heavy smoker consuming 60 cigarettes a day, but ceased smoking 16 years prior to transplantation. He had past history of thyroidectomy in 2001, a surgical repair for diaphragmatic hernia in 1992 and tonsillectomy in 1966. He has no family history of renal disease or malignancy.

Induction with Bailiximab (simulect) was given at the time of transplantation. He was then maintained on prednisolone, cyclosporine and azathioprine. The procedure was uneventful and his serum creatinine dropped to $2.3 \mathrm{mg} / \mathrm{dl}$ by the fourth post-operative day and stabilized at this level. He had an episode of rejection treated with pulses of methyl prednisolone. After transplantation he developed anemia resulting from bleeding piles, and needed treatment for amoebic dysentery and for conjunctivitis.

The patient was re-admitted to the hospital three months after transplantation because of severe urinary tract infection (UTI) and anemia. His serum creatinine was $1.7 \mathrm{mg} / \mathrm{dl}$ and his hemoglobin level was $7.1 \mathrm{gm} / \mathrm{dl}$ at the time of admission. On examination he was found to have wide-spread skin lesions that were non-irritant, dark in color and nodular in shape. The patient was treated for the UTI with antibiotics and the anemia was corrected with iron supplements and Erythropoietin.

Biopsy of the skin lesion showed a tumor composed of proliferating vessels, mainly capillary size, in the dermis. It contained some spindle shaped cells and focal collection of lymphocytes (Figure 2). The diagnosis of Kaposi's sarcoma was confirmed. The patient's immunosuppressant medications were modified. Cyclosporine and azathioprine were substituted by 
Figure 1: Kaposi's sarcoma nodular lesions in the arms of the patient (left) and regression of Kaposi's sarcoma after two months of treatment with Sirolimus (right)

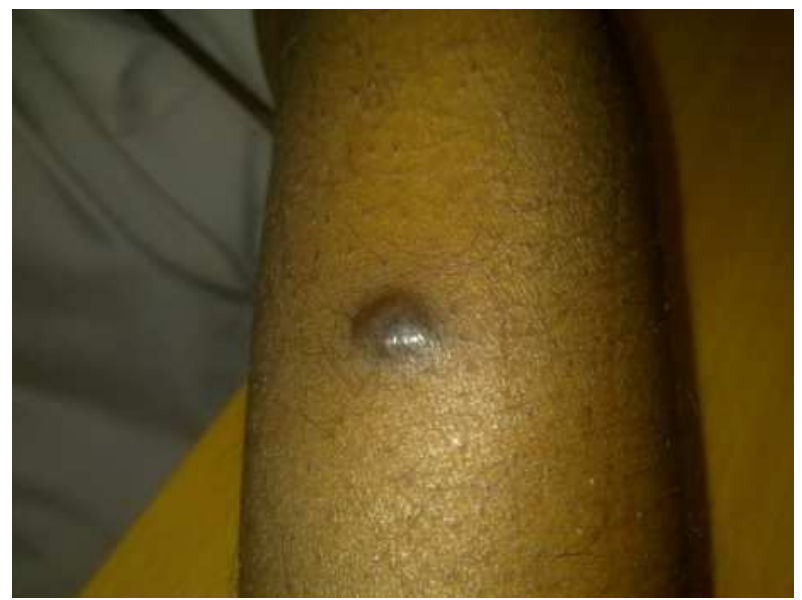

sirolimus $2 \mathrm{mg} /$ day and mycophenolate mofetil $500 \mathrm{mg}$ twice a day. The patient showed a good response after two months of treatment. The tumor size regressed significantly and his graft function was stable with serum creatinine level of $1.1 \mathrm{mg} / \mathrm{dl}$ (figure 1).

\section{Discussion}

Kaposi's sarcoma (KS) is a relatively common malignancy after kidney and solid organ transplantation, accounting for up to $80 \%$ of all malignancies in those patients in developing countries [3]. The incidence varies according to the geographical area. In a report from the same country (Sudan), a total number of 168 biopsies from skin tumors were reported at EL Zahrawy Laboratory between January 2000 and June 2008, of which Kaposi's sarcoma constituted 25 cases (14.88\%) (unpublished data). This figure was only $3 \%$ before the HIV-AIDS pandemic.

In this case, the patient developed Kaposi sarcoma shortly after transplantation. This could be related to the higher susceptibility among people of African descent.

In a report from single Saudi center, a cohort of 30 Sudanese kidney transplant recipients was followed for 16 years. Four patients $(13.3 \%)$ developed KS within 4-36 months after transplantation. All patients were HIV negative. The authors concluded that the incidence of KS in Sudanese renal transplant recipients was very high, supporting the theory of racial or geographic factors in its genesis [4].

This early onset may also be related to the fact that he received induction therapy and required a course of pulse steroids for the treatment of acute rejection. Immunosuppressive medications reactivate human herpes virus 8 , which has been proposed as the offending

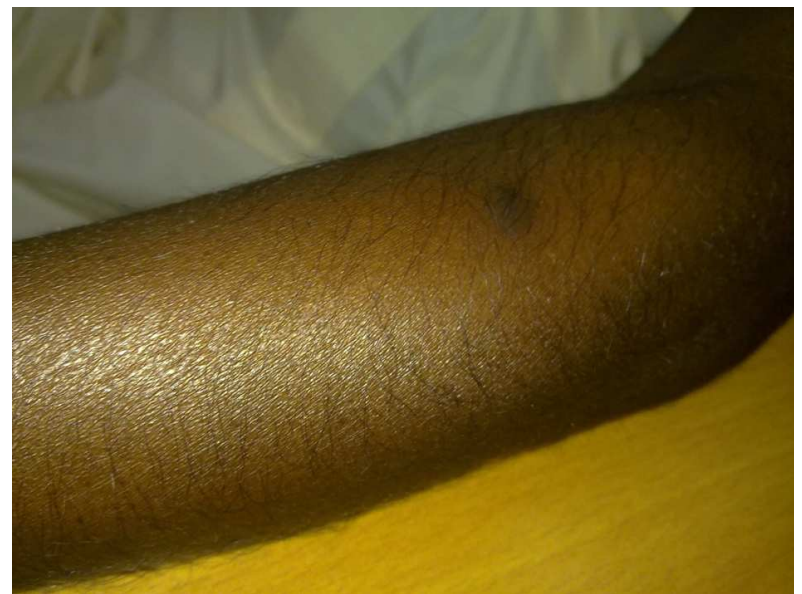

agent. [5-7] The increased incidence of disease in transplant populations may, in part, be attributed to the choice of immunosuppressive regimen. Calcineurin inhibitors (CNIs) are associated with a higher incidence of this tumour [8]. Males and patients on azathioprine are also more prone to $\mathrm{KS}[9,10]$. Conversion to sirolimus treatment was reported as effective therapy for $\mathrm{KS}$ in transplant patients. Recurrence of KS after increasing sirolimus dose suggests that regression of $\mathrm{KS}$ is a result of diminished immunosuppression, rather than a direct antineoplastic effect of sirolimus. Careful maintenance of low sirolimus levels is suggested [5, 11-13]. Reduction of transplant medication alone may be curative in some patients [9].

The high cumulative incidence of malignancies after kidney transplantation makes it imperative to define an effective safe immunosuppressive regimen. The prime approach to treatment of post-transplantation malignancies should begin with early detection and ensuing aggressive treatment to improve the outcome.

\section{Conclusion}

Kaposi sarcoma can occur shortly after transplantation in men of African descent. This report confirms earlier reports about the beneficial effect of sirolimus in causing regression of KS lesions.

\section{References}

1. Kasiske BL, Snyder JJ, Gilbertson DT, Wang C. Cancer after kidney transplantation in the United States. Am J Transplant. 2004 Jun;4(6):905-13. 
Figure 2: Histopathology of the patient's Kaposi sarcoma lesion: (A) vessels of variable sizes and some spindle shaped cells are the two main features of the tumour (B) capillaries with extravasation of red cells are commonly encountered in Kaposi's sarcoma (C) part of the tumour consists mainly of spindle shaped cells and collagen (D) part of a nodule of Kaposi's sarcoma in the skin showing a mononuclear cell infiltrate at one margin (Arrow) (H\&E x 40)
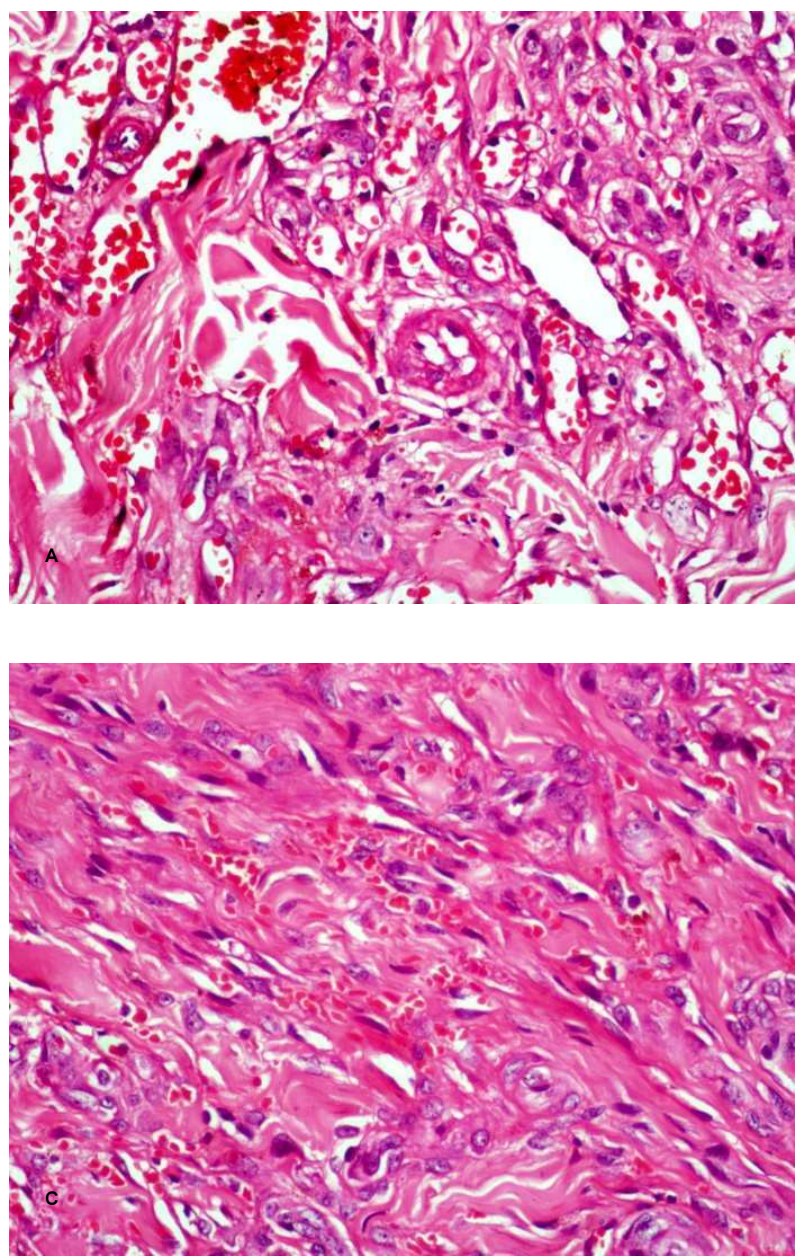

2. Euvrard S, Kanitakis J, Claudy A. Skin cancers after organ transplantation. N Engl J Med. 2003 Apr 24;348(17):1681-91.

3. Moosa MR. Kaposi's sarcoma in kidney transplant recipients: a 23-year experience. Qjm. 2005 Mar;98(3): 205-14.

4. Sabeel AI, Qunibi WY, Alfurayh OA, Al-Meshari K. Kaposi's sarcoma in Sudanese renal transplant recipients: a report from a single center. J Nephrol. 2003 MayJun;16(3):412-6.

6. Caterino-de-Araujo A, Manuel RC, Bianco RD, Santos-Fortuna E, Magri MC, Silva JM, Bastos R. First survey for detecting the presence of human herpesvirus 8 infection (HHV-8) in Maputo, Mozambique. Braz J Infect Dis. 2009 Jun;13(3):200-2.
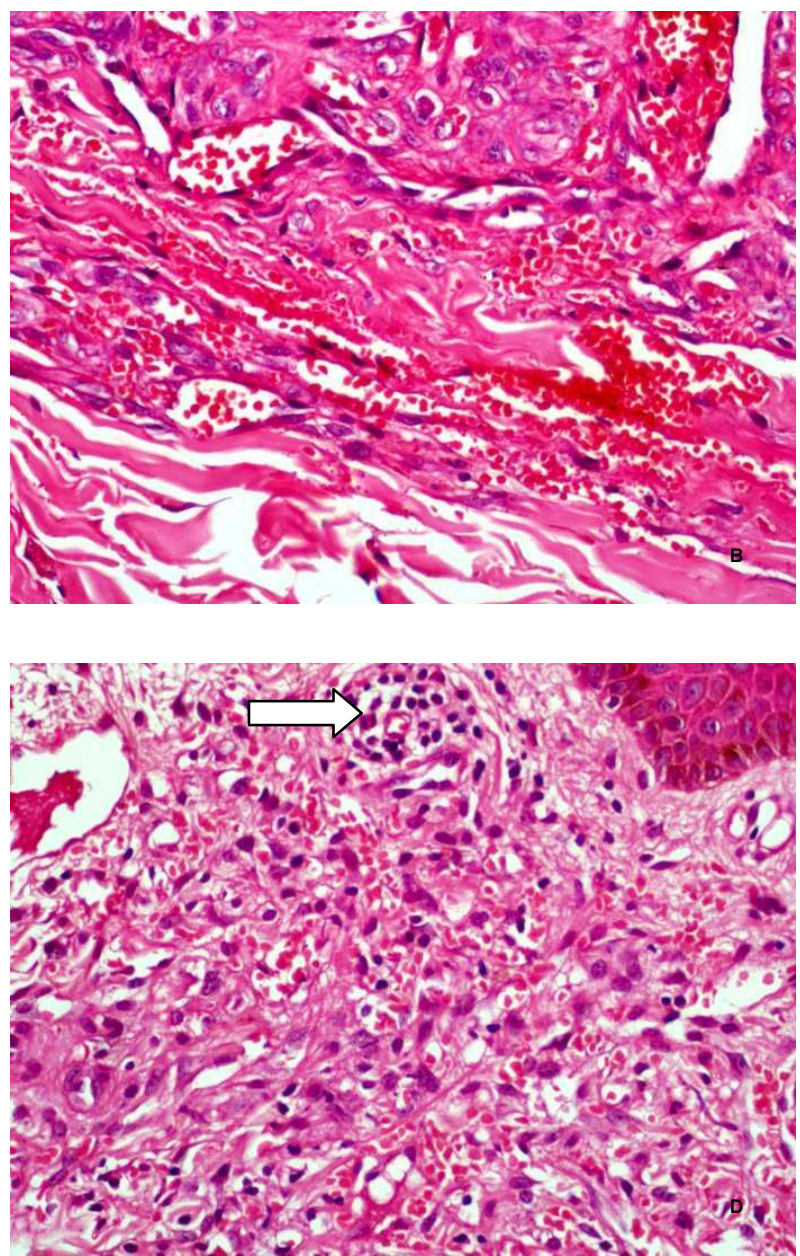

7. Qunibi W, Al-Furayh O, Almeshari K, Lin SF, Sun R, Heston L, Ross D, Rigsby M, Miller G. Serologic association of human herpesvirus eight with posttransplant Kaposi's sarcoma in Saudi Arabia. Transplantation. 1998 Feb;65(4):583-5.

8. Campistol JM, Schena FP. Kaposi's sarcoma in renal transplant recipients:the impact of proliferation signal inhibitors. Nephrol Dial Transplant. 2007 May;22 Suppl $1: 117-22$.

9. Duman S, Töz H, Așçi G, Alper S, Ozkahya M, Unal I, Celik A, Ok E, Bașçi A. Successful treatment of post-transplant Kaposi's sarcoma by reduction of immunosuppression. Nephrol Dial Transplant. 2002 May;17(5):892-6. 
10. Zmonarski SC, Boratyńska M, Puziewicz-Zmonarska A, Kazimierczak K, Klinger M. Kaposi's sarcoma in renal transplant recipients. Ann Transplant. 2005;10(2):59-65.

11. Boratynska M, Zmonarski SC, Klinger M. Reccurence of Kaposi's sarcoma after increased exposure to sirolimus. Int Immunopharmacol. 2006 Dec;6(13-14):2018-22.

12. Charfi S, Krichen-Makni S, Yaich S, Makni H, Khabir A, Amouri A, Charfeddine K, Hachicha J,
Sellami-Boudawara T. Successful treatment of post-renal transplant gastric and pulmonary Kaposi's sarcoma with conversion to rapamycin treatment. Saudi J Kidney Dis Transpl. 2007 Nov;18(4):617-20.

13. Yang TC, Shu KH, Cheng CH, Wu MJ, Lian JD. Malignancy following renal transplantation. Zhonghua Yi Xue Za Zhi (Taipei). 1998;61(5):281-8. 